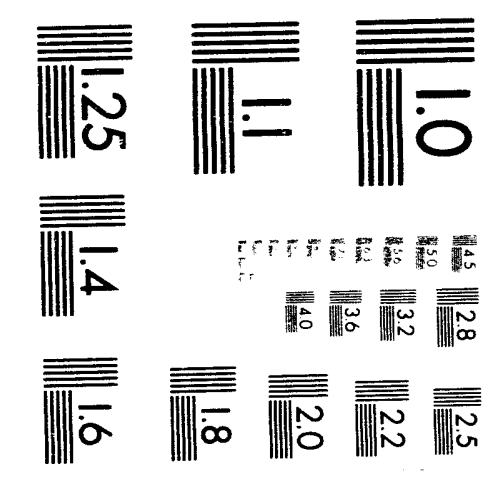



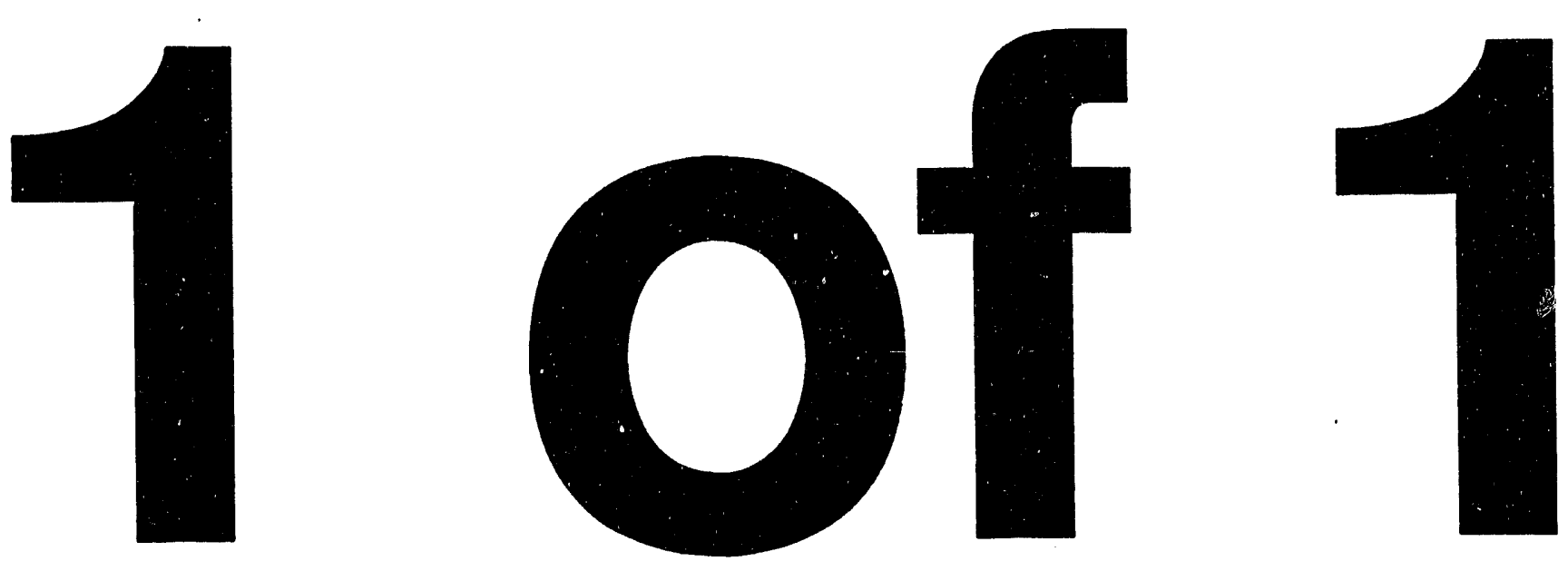
GA-A21426

\title{
SURFACE IMPURITY REMOVAL FROM DIII-D GRAPHITE TILES BY BORON CARBIDE GRIT BLASTING
}

\author{
by \\ R.L. LEE, M.A. HOLLERBACH, K.L. HOLTROP, \\ A.G. KELLMAN, P.L. TAYLOR, W.P. WEST
}

This is a preprint of a paper to be presented at the 15th IEEE/NPSS Symposium on Fusion Engineering, October 11-15, 1993, in Hyannis, Massachusetts, and to be printed in the Proceedings.

Work supported by

U.S. Department of Energy

Contract DE-AC03-89ER51114

GENERAL ATOMICS PROJECT 3466

NOVEMBER 1993

\section{GENERAL ATOMICS}




\title{
SURFACE IMPURITY REMOVAL FROM DIII-D GRAPHITE TILES BY BORON CARBIDE GRIT BLASTING*
}

\author{
R.L. Lee, M.A. Hollerbach, K.L. Holtrop, \\ A.G. Kellman, P.L. Taylor, W.P. West \\ General Atomics \\ P.O. Box 85608, San Diego, California 92186-9784
}

\begin{abstract}
During the latter half of 1992 , the DIII-D tokamak at General Atomics (GA) underwent several modifications of its interior. One of the major tasks involved the removal of accumulated metallic impurities from the surface of the graphite tiles used to line the plasma facing surfaces inside of the tokamak. Approximately 1500 graphite tiles and 100 boron nitride tiles from the tokamak were cleaned to remove the metallic impurities. The cleaning process consisted of several $s_{1}, ' s$ : the removed graphite tiles were permanently marked, surface blasted using boron carbide $\left(\mathrm{B}_{4} \mathrm{C}\right)$ grit media (approximately $37 \mu \mathrm{m}$. diam.), ultrasonically cleaned in ethanol to remove loose dust, and outgassed at $1000^{\circ} \mathrm{C}$. Tests were done using graphite samples and different grit blaster settings to determine the optimum propellant and abrasive media pressures to remove a graphite layer approximately 40-50 $\mu \mathrm{m}$ deep and yet produce a reasonably smooth finish. EDX and beta-backscattering measurements revealed that the blasting technique reduced the surface $\mathrm{Ni}, \mathrm{Cr}$, and $\mathrm{Fe}$ inpurity levels to those of virgin graphite. Auger analysis of blasted tile samples does not show surface inpurities within the first few atomic layers. An estimate of the depth of surface roughness due to the $\mathrm{B}_{4} \mathrm{C}$. abrasive action is $\pm 20 \mu \mathrm{m}$. In addition to the surface impurity removal, tritium monitoring was performed uhroughout the cleaning process. A bubbler system was set up to monitor the tritium level in the exhaust gas from the grit blaster unit. Surface wipes were also performed on over $10 \%$ of the tiles. Typical surface tritium concentrations of the tiles were reduced from about $500 \mathrm{dpm} / 100 \mathrm{~cm}^{2}$ to less than $80 \mathrm{dpm} / 100 \mathrm{~cm}^{2}$ following the cleaning. This tile conditioning, and the installation of additional graphite tiles to cover a high fraction of the metallic plasma facing surfaces, has substantially reduced metallic impurities in the plasma discharges which has alowed rapid recovery from a seven-month machine opening and regimes of enhanced plasma energy confinement to be more readily obtained. Safety issues concerning blaster operator exposure to carcinogenic metals and radioactive tritium will also be addressed.
\end{abstract}

\section{INTRODUCTION}

During the latter half of 1992, the DIII-D tokiunak at GA underwent several modifications of its interior [1]. One of the major tasks involved the removal of accumulated metallic impurities from the surface of the graphite armor tiles. Scanning electron microscope (SEM) photographs of tiles removed from DIII-D revealed that most of the $\mathrm{Ni}, \mathrm{Cr}$, and $\mathrm{Fe}$ impurities were within the top $20 \mu \mathrm{m}$. of the tile surface. Impurity influx into the discharges often results in degraded plasma performance. The dominant metallic impurity in the plasma discharges was nickel, which is the major component of the Inconel vessel wall. Iron, chromium, copper, and bromine were also present as impurities in the discharges. Fig. 1 is an energy dispersive X-ray, or EDX, scan of a tile removed from DIII-D prior to grit blasting showing peaks for the main metallic impurities. The relatively high proportion of $\mathrm{Ni}$ and $\mathrm{Cr}$ species are clearly evident and detectable amounts of $\mathrm{Cu}, \mathrm{Al}, \mathrm{Ti}$, and $\mathrm{Fe}$ above background are present as well. The $\mathrm{Au}$ lines result from a conductive gold coating purposely applied to the sample before placement into the EDX analysis chamber to reduce charge effects which interfere with the analysis. To reduce the influx of impurity atoms it was decided to fully line the plasma facing Inconel susfaces of the machine interior with graphite tiles. Interior surfaces of port were not lined with tiles. The added til's increased the armor coverage of the wall surfaces immidiately adjacent to the

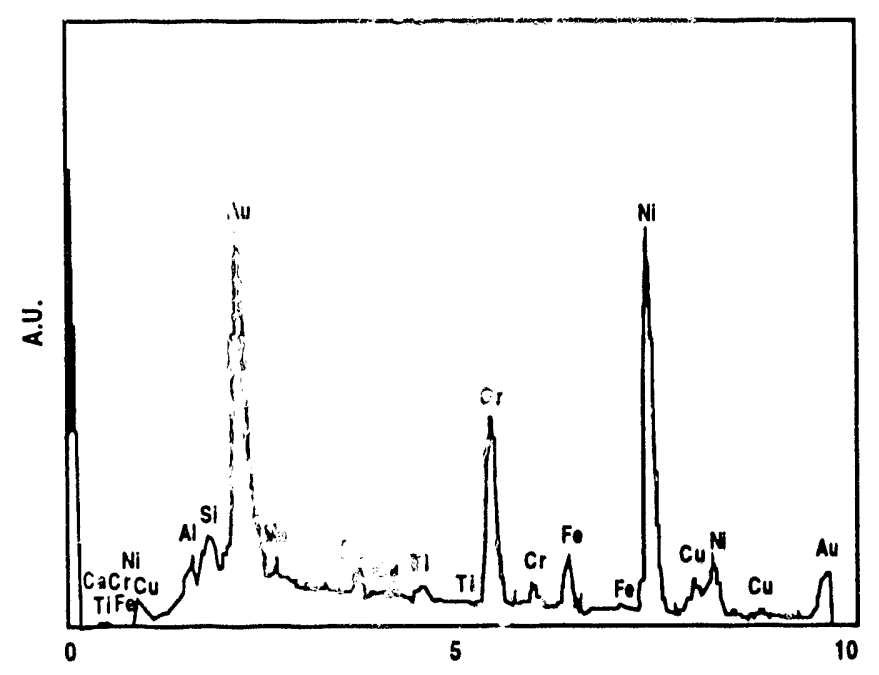

Fig. 1. Energy dispersive X-ray (EDX) analysis of a nongrit blasted tile clearly shows metallic impurities.

\footnotetext{
*Manuscript received Octoher 14, 1993. This work was sponsored by the U.S. Department of Energy under Contract No. DE-AC03-89ER51114.
} 
plasma from about $40 \%$ to nearly $100 \%$. Concurrent with the addition of new tiles to DIII-D, all of the old tiles were removed and cleaned to remove surface impurities. The goal of the cleaning process was to remove $\mathrm{Ni}, \mathrm{Cr}, \mathrm{Fe}, \mathrm{Cu}$, and $\mathrm{Br}$ from the tile surfaces. Approximately 1500 graphite tiles and 100 boron nitride tiles were removed from the tokamak and processed.

\section{CLEANING PROCEDURE}

The cleaning procedure for the tiles removed from DIII-D consisted of several steps: First, surface wipes were taken on approximately $10 \%$ of the tiles to measure removable surface tritium, alpha, and beta contamination levels. Second, each of the removed graphite tiles was permanently marked with its toroidal and poloidal locations and tile type using a hand-held vibration etcher [2]. Next, the tiles were grit blasted using boron carbide media and ultrasonically rinsed in ethyl alcohol to remove loose graphite and media dust. Boron carbide media blasting has been successfully performed in TEXTOR to clean graphite limiter blades [3]. A different tile surface cleaning technique using silicon carbide sandpaper and scouring pads has been used on TFTR [4]. For the tiles removed from DIII-D, the grit hlasting method was chosen because it offered an efficient way to clean a large number of tiles. The final stage of tile cleaning consisted of outgassing the tiles at $1000^{\circ} \mathrm{C}$. for $4 \mathrm{~h}$ to remove residual trapped alcohol and other gases within the tile bulk. Throughout the entire process, each tile was carefully tracked using log sheets which indicated the status of each tile. Any broken or chipped tiles were repaired or replaced when necessiry.

The dry abrasive blaster used for grit blasting was from Media Blast \& Abrasives. The unit was a negative pressure, dual chamber model [5]. The unit was chosen for its ability to trap residual particles which may have a low level of radioactive or carcinogenic contamination. Negative pressure in the blaster unit was developed from a built-in high speed fan having a throughput velocity of $20 \mathrm{~m}^{3} / \mathrm{min}$ on the exhaust port of the unit. A cyclone separator exhausted all light graphite and boron carbide dust through the filters while allowing the heavier abrasive boron carbide particulates to be recycled through the unit. The filtering system included an inlet filter set, an intermediate dual canister filter set, and a high efficiency particulate (HEPA) filter on the exhaust port. The HEPA filter trapped all particles greater than $0.12 \mu \mathrm{m}$.

Boron carbide was used as the blasting media because it is an effective abrasive for graphite and the presence of residual boron carbide on the tiles is acceptable for plasma operations since boron is a low $\mathrm{Z}$ element and is generally present on the graphite surfaces from frequent wall conditioning boronizations of DIII-D. The spray pattern from the boron carbide nozzle was circular with an angular width of about $22 \mathrm{deg}$. The media grit size was approximately $37 \mu \mathrm{m}$, but varied from 20 to $65 \mu \mathrm{m} \mathrm{[6].} \mathrm{Grit} \mathrm{smaller} \mathrm{than} \mathrm{about} 20 \mu \mathrm{m}$ was not utilized effectively by the blaster unit and particles larger than about $60 \mu \mathrm{m}$ may remove more of the graphite tile surface than was desired, although no measurements to assess this effect were done. A manually operated expanded metal turntable inside the blasting chamber allowed for rotation of the target tiles during blasting operations. A small graphite shelf was made on which to place the tiles during grit blasting to keep the media gun from discharging directly onto the expanded metal of the turntable or the interior steel walls of the chamber thus avoiding undue metallic contamination. Before grit blasting any armor tiles, graphite removal rates were determined by grit blasting graphite test coupons $(4 x$ $4 \times 1 \mathrm{~cm}$ ) using various blaster settings. Room temperature gaseous nitrogen propellant pressure was varied from 10 to $30 \mathrm{psi}$. The gas was taken from $\mathrm{LN}_{2}$ boil-off to ensure minimal contamination. The media delivery pressure, which affected the particle density, was changed between 5 and $10 \mathrm{psi}$. The distance between the media gun nozzle and tile surface was 15 to $20 \mathrm{~cm}$ and the nozzle was kept perpendicular to the surface being cleaned. The depth of material removed per pass varied from 2.2 to $22 \mu \mathrm{m}$ and was linear with either the propellant or media pressure.

Auger measurements indicated the impurities were present to a depth of approximately $30 \mu \mathrm{m}$ beneath the tile surface. Thus, the working range for propellant and media pressure values and the number of passes was chosen so that the total removed depth of material was between 25 and $50 \mu \mathrm{m}$. When grit blasting the plasina facing surfaces of the tiles, we chose to obtain this depth in three passes of the media nozzle which would retain a relatively good surface flatness without excessive material being removed or producing gouging during any single pass. The settings used included a propellant pressure of $25 \mathrm{psi}$ and a media pressure of $15 \mathrm{psi}$. The first and second passes were orthogonal to each other and the third pass was at a 45 deg angle with respect to the first two passes. The remainder of the tile surface, including sides, feet, and bottom, received three passes as well. Three tiles at a time were placed into the blisting chamber. The operator timed the overall blasting process and turned the tiles when required. The plasma facing surface on each tile was blasted for approximately 1 to 1.5 minutes, to remove primarily metallic impurities. Bromine had previously been found on nonplasma facing surfaces of some tiles and these surfaces of each tile were blasted for a total of 2 minutes. The abrasive action of the grit was reduced after repeated use and replacement of the $18 \mathrm{~kg}$ media charge was performed after approximately 300 tiles were cleaned.

Operator safety while handling and processing the tiles was an inportant part of the overall cleaning process. While operating, the media blaster unit was fully sealed and under negative pressure. Graphite particulates, some of which contained carcinogenic nickel atoms, and boron carbide grit were contained within the blaster unit during operation. However, had there been a catastrophic failure of the sealing portions or filtering systems of the blaster, it was estimated that approximately $4 \mathrm{~g}$ of graphite and boron carbide could be 
ejected from the unit during a $30 \mathrm{sec}$ shutdown period. Calculations of the resulting particulate and nickel volumeaveraged concentrations would he $6 \mathrm{mg} / \mathrm{m}^{3}$ and $0.05 \mathrm{mg} / \mathrm{m}^{3}$, respectively, below levels requiring a face mask. Thus, a face mask was not required during normal operations of the blaster, but was used while transferring tiles to and from the blaster unit. Calculations also showed that without proper ventilation a high level of the nitrogen propellant from the blaster might accumulate, thereby reduciang the available oxygen level. Hence, external ventilation of the exhaust was established using $30 \mathrm{~cm}$ ducting compatable with the blaster unit's throughput volume.

Analyses for the presence of residual radioactive species were performed to determine safe handling procedures and document the quantity of radioactive species present. A tritium bubbler system was used to monitor grit blaster and vacuum-oven exhausts for the presence of released tritium [7]. Surface wipes which measure removable alpha, beta, and tritium species were done on many tiles. No amounts of removeable alpha or beta species above hackground were found. No neutron activation above background was observed in the tiles. However, on many tiles, tritium was found to be located both on the surface of the tile and in the bulk. Surface wipes for tritium revealed concentrations ranging from a background level of $40 \mathrm{dpm} / 100 \mathrm{~cm}^{2}$ on a ceiling tile to a maximum of $3400 \mathrm{dpm} / 100 \mathrm{~cm}^{2}$ found on one of the limiter tiles. The maximum surface tritium level for unrestricted release is $1000 \mathrm{dpm} / 100 \mathrm{~cm}^{2}$. Measurements of tritium released during high temperature bakes of some blasted and unblasted tile samples revealed that about $96 \%$ of the tritium was removed by the grit blasting. Thus, the tiles were able 10 safely go off-site for baking without restrictions. Contaminated graphite particles were trapped by the filtering system. Latex gloves were used when handling the tiles and contaminated grit was transferred to Health Physics for inventory and disposal.

\section{TILE SURFACE IMPURITIES AND THEIR REMOVAL}

The tiles are made from ATJ graphite, which has a total ash, or impurity, content between $0.1 \%$ and $0.2 \%$. Over $80 \%$ of these impurities include S, Ca, Fe, and V [8]. Other impurities present in the bulk material include small anounts of $\mathrm{Al}, \mathrm{Ti}, \mathrm{Ni}, \mathrm{Si}$, and $\mathrm{Pb}$. The deposition of metallic impurities on the surface of DIII-D tiles and subsequent analysis using external particle induced X-ray (X-PIXE) techniques have been previously reported [9]. However, during the present tile reconditioning task, the methods used for observing metallic impurities on the tile surface were Auger analysis and a $\beta$ back-scatter microphotographic technique. A portable $\beta$-backscatter probe was also used for estimating gross impurity removal effectiveness, but was not calibrated for any particular metallic species. Fig. 2 is a $\beta$-back-scatter microphotograph $(350 x)$ showing the surface edge of a tile prior to blasting. The bright regions along the edge of the surface are metallic impurities in the unblasted graphite

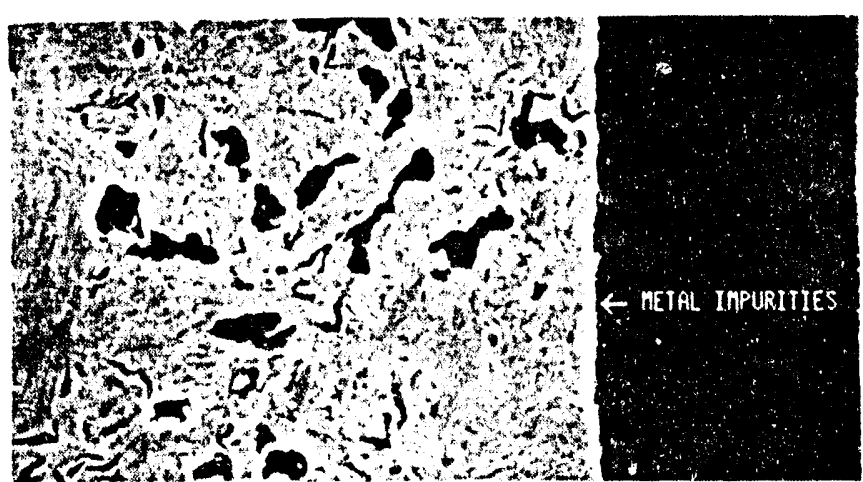

Fig. 2. Metallic impurities are evident along the surface of a sectioned tile removed from DIII-D prior to grit blasting $(350 x)$.

surface. The metallic impurities are within the top 5 to $10 \mu \mathrm{m}$ of the plasma striking surface of the tiles, but due to the open porosity of the graphite, some inpurities are present along the imer perimeter of the surface pores. The pores are typically 1.5 to $20 \mu \mathrm{m}$ deep and, therefore, the effective depth of impurity concentration may be up to $30 \mu \mathrm{m}$.

Fig. 3 is a microphotograph $(100 x)$ of the profile of a tile surface which has been grit blasted. No metals are evident on the surface of the tile or within any of the open surface pores. Comparison of this figure with the previous one shows the blasted surface is rougher than that of the unblasted sample. Measurements of the surface irregularity shows a maximum prolile height of $16 \mu \mathrm{m}$ for the unblasted sample and $36 \mu \mathrm{m}$ for that of the blasted saunple. EDX scans made of blasted tile surfaces do not show metallic contamination above that of background.

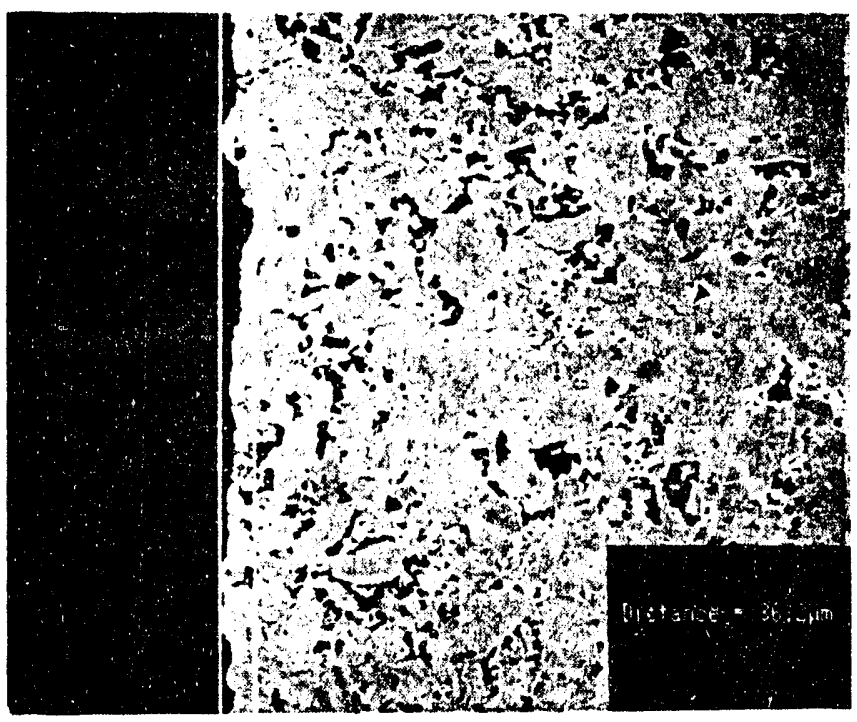

Fig. 3. The surface of a grit blasted tile shows no metallic impurities $(100 x)$. 


\section{SUMMARY}

Over 1600 graph $: e$ and boron nitride tiles were removed from DIII-D for surface cleaning using boron carbide grit blasting and high temperature baking procedures. The major surface impurities, $\mathrm{Ni}, \mathrm{Fe}, \mathrm{Cr}, \mathrm{Cu}$, and $\mathrm{Br}$ were effectively removed without damage to the tiles during the grit blasting. Ultrasonic cleaning of the tiles in alcohol followed by high temperature baking insured that no residual loose horon carbide dust or alcohol were left in the tiles. In addition, tritium monitoring of sample lots of the tiles during grit blasting and bake-out indicate that more than $96 \%$ of tritium is removed during the entire procedure. The process of cleaning the existing tiles along with covering the additional plasma facing metallic surfaces with new tiles successfully reduced plasma impurities and led to enhanced plasma performance.

\section{ACKNOWLEDGMENTS}

The authors wish to extend their appreciation to the DIII-D technical staff for their expert assistance during all phases of the tile reconditioning and installation process. We also wish to extend thanks to Don Wall, who prepared the Auger and EDX data.

\section{REFERENCES}

[1] Hollerbach, M., R.L. Lee, D.L. Sevier, J.P. Smith, and P.L. Taylor, "Upgrade of the DIII-D vacuum vessel protection system," to he published in Proc. 15th IEEE/NPSS Symp. on Fusion Engineerıng.

[2] Hollerbach, M., "Procedure for the grit blasting of DIII-D graphite armor tiles," General Atomics Tech. Spec. 4-2106.17TS.

[3] Dippel, K., H.W. Kolilhaas, C. Stickelmann, "Cleaning of metalcontaminated graphite tiles of the TEXTOR ALT-II pump limiter blades," J. Nucl. Mater. 168 (1989) 58-64.

[4] Clirzanowski. J.H., "Edge feathering and removal of surface metals from bumper limiter tiles," TFTR Operations Procedure OP-1O-217. March 1991.

15] Media Blast \& Abrasives. Inc., 5126 Chakemco St. P.O. Box 1264. Scuth Gate, California.

[6] AGSCO Corp. Wheeling. Illinois.

[7] Taylor, P.L., A.G. Kellman, R.L. Lee, "Tritium in the DIII-D carbon tiles," J. Fusion Energy, in press.

[8] UCAR, Cleveland, Ohio.

[?] Walsh. D.S., B.L. Doyle, G.L. Jackson, "Deposition of deuterium and metals on divertor tiles in the DIII-D tolkamak," J. Vac. Sci. Tectimol. A 10(4) (1992) 1174. 

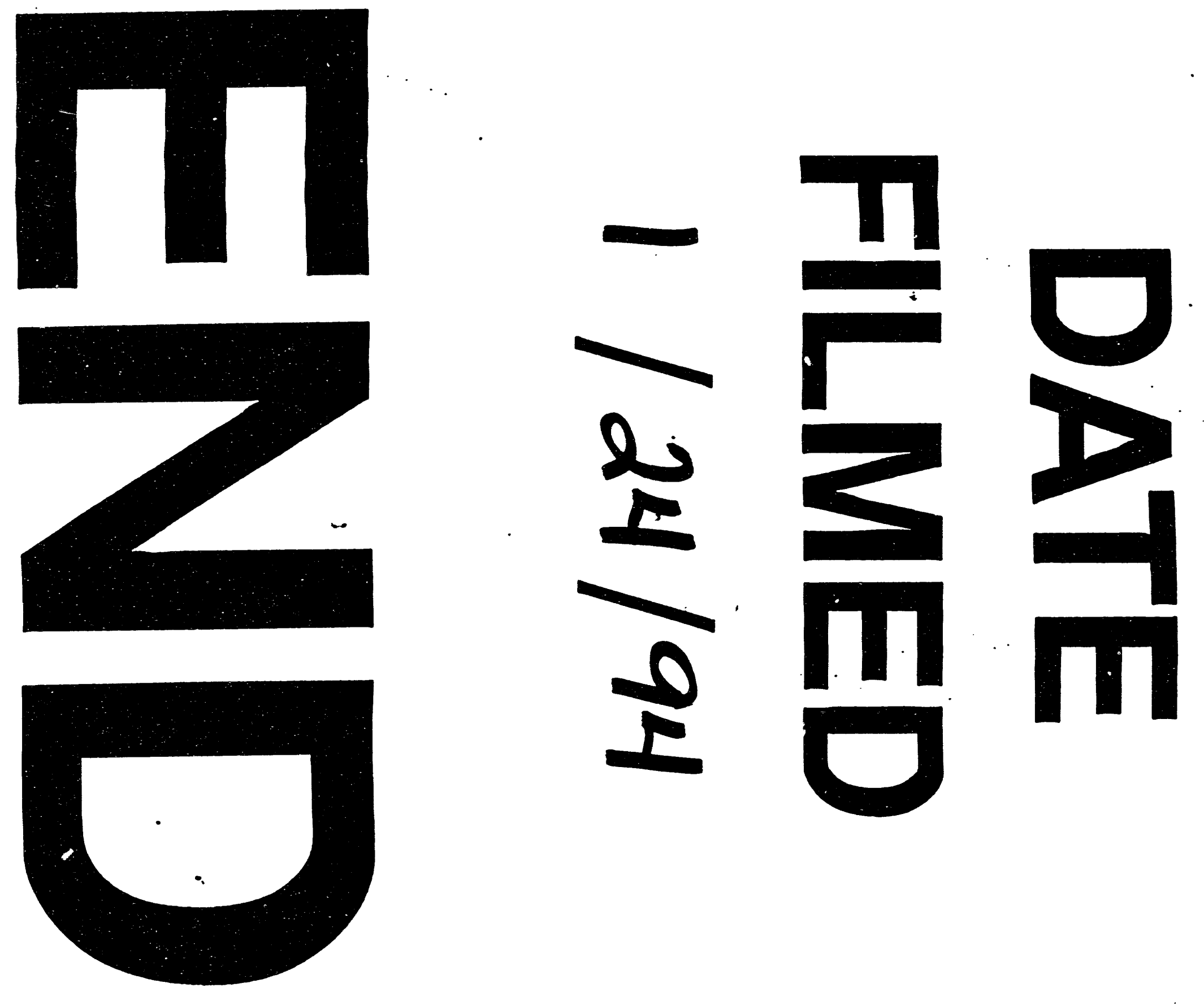
